Copyright (@ 2009 Institute of Electrical and electronics Engineers, Inc.

All Rights reserved.

Personal use of this material, including one hard copy reproduction, is permitted.

Permission to reprint, republish and/or distribute this material in whole or in part for any other purposes must be obtained from the IEEE.

For information on obtaining permission, send an e-mail message to stds-igr@ieee.org.

By choosing to view this document, you agree to all provisions of the copyright laws protecting it.

Individual documents posted on this site may carry slightly different copyright restrictions.

For specific document information, check the copyright notice at the beginning of each document. 


\title{
Challenges of Asset Management in Power Transmission Network
}

\author{
Lutfiye Allahmanli ${ }^{1}$, Gopi Chattopadhyay ${ }^{2}$ and Gary Edwards ${ }^{3}$ \\ ${ }^{1,2}$ Central Queensland University, Gladstone campus, Qld 4680, AUSTRALIA, \\ g.chattopadhyay@cqu.edu.au \\ ${ }^{3}$ Powerlink Queensland, 33 Harold Street, Qld 4014, AUSTRALIA, \\ gedwards@powerlink.com.au
}

\begin{abstract}
Managing Assets in capital intensive industries such as Power Transmission has been becoming more complex due to uncertainties with long asset life, inspection and maintenance in remote places, environmental factors, statutory requirements along with deregulation and competition in the open market.
\end{abstract}

In this paper, the possible challenges are explained with illustrative examples. Asset management principals for power transmission network companies are emphasized. The hierarchal levels within asset management approach are shown with highlighting the importance of relationship between each level.

Keywords - Asset Management, PAS55, Power Transmission Network

\section{INTRODUCTION}

Transmission is the backbone of the power distribution system. A well planned, properly designed and well maintained transmission network can provide reliable and quality power supply to customers. The transmission lines, underground cables, and various equipments such as transformers, reactors, circuit breakers, insulators, instrument transformers, surge arrestors, conductors, and tap changers constitute major part of a transmission system [14].

In relation to asset management, supplying reliable power is one of the key aspects in transmission network system. Supply reliability is significantly influenced by network structure and element condition and are influenced by asset management strategies [13].

Today many organizations are implementing asset management methodologies to improve overall operational efficiency. There are many developments in recent years for getting best out of the assets. This is mainly due to deregulation and though competition in the open market.

The outline of this paper is as follows: Section 1 provides the introduction followed by background in Section 2 . Section 3 outlines challenges and feasible solutions with applying asset management methodology to system elements. Concluding summary is presented in the final section.

\section{BACKGROUND}

Most Power Transmission companies are network monopolies, which currently operate within a framework of economic regulation. The economic regulator sets targets for both economic efficiency and network performance (reliability and quality). Achieving economic efficiency is relatively less difficult if one is not concerned with supply reliability. Similarly, achieving reliability is relatively less difficult if one is not concerned with costs and penalties. But simultaneously achieving both reliability and economic efficiency is challenging, requiring a systematic and scientific approach. This necessitates a practical Asset Management Strategy, to balance the competing aims of cost effectiveness and reliability of supply to consumers. There are a number of major constraints and obligations related to transmission network. These are as follows:

- Environment and Safety - ensuring that environmental and safety regulations are met,

- Demand and Growth Management involving capital projects with efficient planning and management of CAPEX,

- Customer \& stakeholder \& community expectations - ensuring that power supply quality meets the customer expectations, and enhances the reputation of the company in the community. Customer expectations are generally specified in formal contractual agreements between customers and Transmission Company.

- Network condition - is linked to the condition of assets and its optimization in cost effective way. It is important to note that many of the transmission assets are in remote locations and that transmission lines are located on third party's property,

- Regulatory Requirements and responsibilities - transmission companies need to meet the service standards requirements set by the regulator. Service standards are associated with performance of assets. To intervene with the market there are incentives and penalties for Transmission Network Service Providers (TNSPs) to encourage responsive network performance from TNSPs during peak periods and extreme events. AER (Australian Energy 
Regulator) develops service standard scheme as outlined and illustrated in Table 1 .

Table 1: Service standards scheme in Australia

\begin{tabular}{|c|c|c|c|}
\hline Service Standard & Target & $\begin{array}{c}\text { Performance } \\
\text { Result }\end{array}$ & $\begin{array}{c}\text { Incentive } \\
\text { (Penalty) } \\
\text { (\$M) }\end{array}$ \\
\hline Circuit Availability (total) & 0 & 0 & $\$ 0.00$ \\
\hline Circuit Availability (critical) & $97.15 \%$ & $96.89 \%$ & $-\$ 0.05$ \\
\hline $\begin{array}{c}\text { Circuit Availability (non- } \\
\text { critical) }\end{array}$ & $97.98 \%$ & $97.99 \%$ & $\$ 0.00$ \\
\hline $\begin{array}{c}\text { Circuit Availability (peak) } \\
\text { Circuit Availability (off-peak) }\end{array}$ & $97.45 \%$ & $96.35 \%$ & $-\$ 0.12$ \\
\hline $\begin{array}{c}\text { Loss of Supply Event Frequency } \\
\text { Index }\end{array}$ & 0 & 0 & $\$ 0.00$ \\
\hline$>0.2$ minutes \# & 4 & 6 & $-\$ 0.12$ \\
\hline$>1.0$ minutes \# & 1 & 1 & $\$ 0.00$ \\
\hline $\begin{array}{c}\text { Average Outage Duration } \\
\text { Transmission Constraints (inter- } \\
\text { regional) } \\
\text { (rvegional) }\end{array}$ & 800 & 1023 & $-\$ 0.06$ \\
\hline $\begin{array}{c}\text { Average Outage Duration } \\
\text { (transformers) }\end{array}$ & 0 & 0 & $\$ 0.00$ \\
\hline $\begin{array}{c}\text { Transmission Constraints (intra- } \\
\text { ratage Duration (lines) }\end{array}$ & 0 & 0 & $\$ 0.00$ \\
\hline
\end{tabular}

In this example the TNSP has to pay $\$ 350,000$ as penalty because of underperforming against desired targets. It shows that power transmission companies are operating under tighter and sensitive conditions. They are requested to address the issues of providing a high quality of service to the customers at reasonable cost under regulatory conditions. This necessitates a practical Asset Management Strategy, to ensure that the network remains in a satisfactory condition while delivering quality of service to the customers. However, it is essential to allocate and spend benefits of network performance by regulator to keep assets at proper condition.

In general asset management is a business approach designed to line up the management of asset related costs to corporate goals. Brown and Humphrey (2005) indicated asset management for transmission and distribution is corporate strategy that seeks to balance performance, cost and risk.

The goals of asset management are;

1. Balance cost, performance and risk

2. Align corporate objectives with spending decisions

3. Create a multilayer asset plan based on accurate and fact-driven process [4].

Schwan et. al (2006) presented a comprehensive asset management approach with focus on the relevance of component reliability prognosis and concluded that in order to validate long term success, the ability to predict network supply reliability is very important and tells that comprehensive asset management model plays a key role in that matter [15].

Mohapatra and Mukhopadhyay (2006) emphasize the importance of Life Cycle Cost (LCC) and strategies for optimizing asset utilization with the integration of risk management [14]. Hoskins et. al (1999) specify the importance of asset management structure model and confirm that reliability data is required - to make decisions in asset management [16].Western Power (WA) proposed comprehensive asset management. Most aspects of the model are in line with PAS 55 and gives good understanding about its assets and help make decisions [17]. Majority of Asset Management Strategies (AM Strategies) in power transmission network are well prepared and implemented. However, the importance of individual elements (substation, lines, or individual equipment such as transformer, relays and similar items) in the network has big impact on supply reliability. Therefore, reliability of elements needs to be carefully analyzed and the impact to the system has to be calculated to be able to deliver customer requirements. The main objective of asset management is to enable a business to meet its service delivery objectives efficiently and effectively. Effective asset management ensures that assets continue to provide value throughout the asset life cycle, at a minimum cost of ownership for the required level of service and consistent with commercial and risk management strategies. This involves management over all phases of the asset life [11]. Figure 1 provides proposed general approach in power transmission network which contains three major aspects in the lifecycle of an asset:

1. Planning and Acquiring: This stage includes "gap analysis" for the need of new assets. During planning and acquiring stage the following points need to be considered to achieve business drivers;

- Sustain defined reliability and quality of supply to customers

- Plan network development in accordance with the transmission authority rules

- Plan to meet corporate requirements

- Predict future demand

- Examine impact of constraints to network

- $\quad$ Identify and assess risks[6].

2. Operating and Maintaining: This step ensures each asset in the transmission network meet required level of service in a defined timeframe with the appropriate maintenance and operating strategies, refurbishment and ongoing condition assessments. The core points in this stage are; 
- Make sure to meet environmental and safety objectives,

- Provide and implement correct maintenance strategies,

- Ensure maintenance plans are satisfied the requirements,

- Monitor and review condition of assets to take appropriate actions where necessary (such as refurbishments),

- Implement strategies for effective spares management,

- Ensure competency for workforce,

- Implement strategies for outage management to reduce the impact to network and reduce system restoration time in case of unplanned outages,

- Plan and manage OPEX effectively,

- Implement work strategies with the combination of resource planning and work program management,

- Analyze and review asset and network performance to take corrective and preventive actions [6].

3. Replacement and Disposal: End of technical and economical life of the asset decisions are made to repair or replace with the conjunction of asset condition and asset age. This stage includes;

- Analysis to identify which assets are getting end of their technical and economical life or that are unreliable, obsolete or unsupported by manufacturer or vendor,

- Determine the options for replacing assets such as timing that the asset will be out of service, the impacts on network in terms of costs and availability [6].

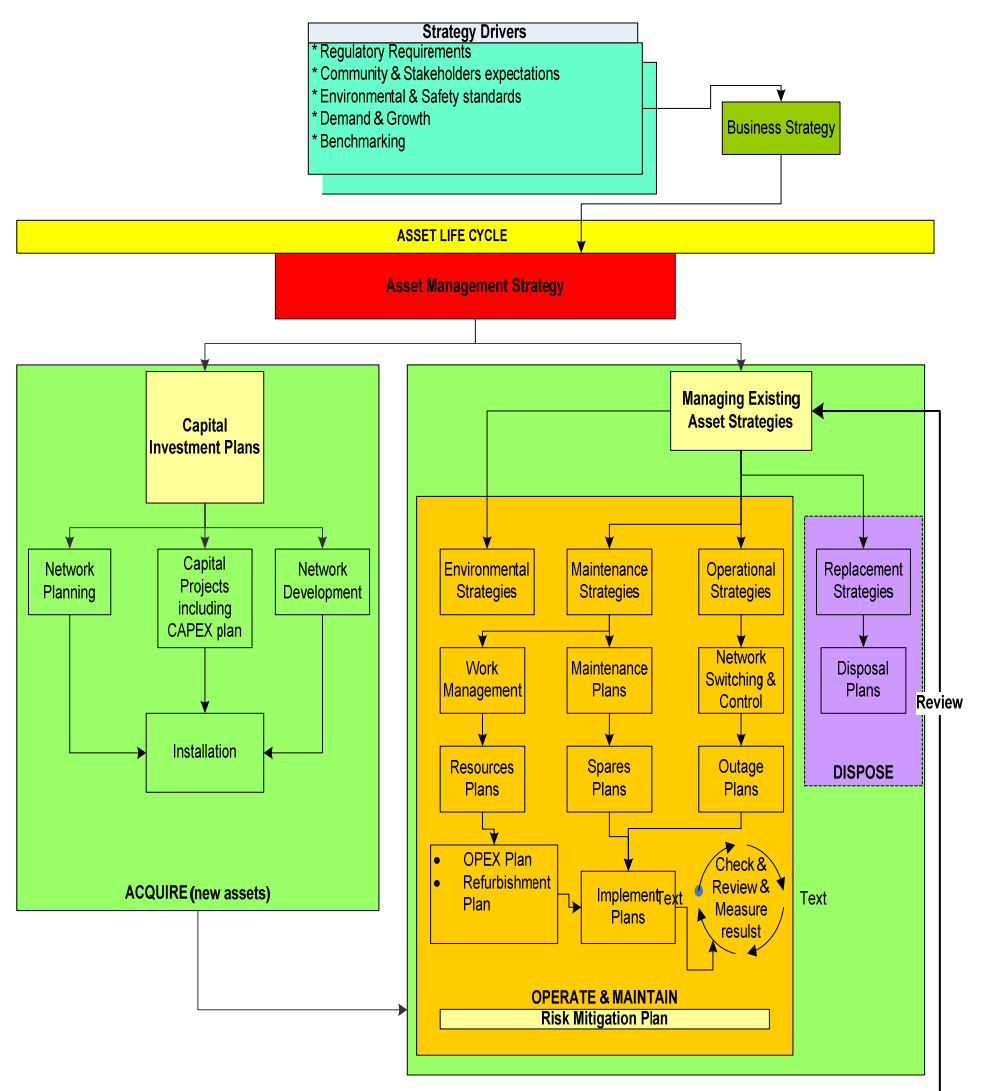

\section{Asset\& Network System Performance Analysis}

Figure 1: Proposed approach to Asset Management in power transmission network

\section{CONCEPTUAL MODEL FOR ASSET MANAGEMENT IN POWER TRANSMISSION NETWORKS}

As mentioned previously asset management model should be developed for each organization based on asset condition, service requirements and business objectives. In other word, asset management model should be specific for each organization. However, the basic fundamentals are same and the main objective is to achieve asset effectiveness targets in a cost effective and sustainable way. 


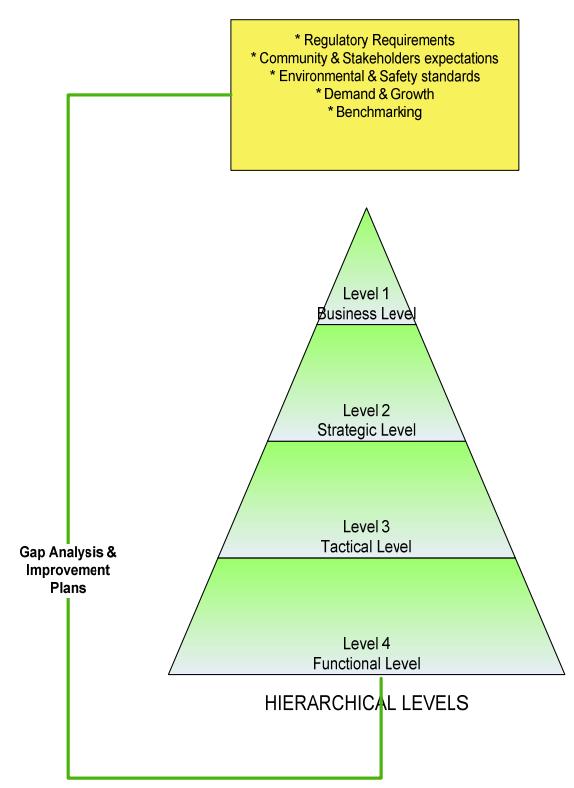

Figure 2: Levels of Asset Management in transmission network

The conceptual model ensures that asset management should is viewed in four hierarchical levels those are business, strategic, tactical and functional levels. The main reason for considering hierarchical levels is to streamline and make the operation sustainable. A sustainable model should provide consistency and positive results in the longer terms.

Business Level (I)

This aspect of the asset management model involves

consideration of;

*Regulatory Requirements

* Community \& Stakeholders expectations

* Environmental \& Safety standards

* Demand \& Growth

* Benchmarking.

Based on the above drivers asset management guidelines, framework and business strategy are developed.

Strategic Level (II)

Asset management strategies need to be in place for the full cycle of an asset's life. The strategies should be set in a broad framework in this level. Reliability and risk management need to be included to all of the asset's life cycle phases linked to asset performance management. This level is to provide strategies for:

- $\quad$ investment in, new assets to meet the long term needs with conjunction of reliability \& risk \& performance management,

- operation and maintenance of existing assets to ensure they deliver safe, reliable and cost-effective services with conjunction of reliability \& risk \& performance management,
- decisions regarding asset refurbishment, replacement \& disposal.

Performance review needs to be undertaken routinely as part of continuous improvement.

Tactical Level (III)

This level includes managing the strategies which were developed in strategic level. It is essential to make sure all the strategies are managed in a sustainable and cost effective way.

Functional Level (IV)

Functional level is responsible from making sure for implementation of all strategies, processes and plans. This includes work management and resources management.

The continuous improvement focuses on four hierarchical levels at every stage of an asset's life.

The main aspect for each box results in asking the following asset management key questions as outlined in Figure 3:

1. Current state of assets--- what are they? Where are they? In what condition (what is the remaining life, what is the economic value)

2. Requirements from assets- what is the expected performance?

3. Which assets are critical to sustained performance? ----- How they fail? How they can fail? What is the risk? What are the associated costs?

4. What are the best options over the life cycle? How to carry out Life Cycle cost analysis?

5. What is the best long term asset plan?

6. What tools and techniques can be used during each stage?

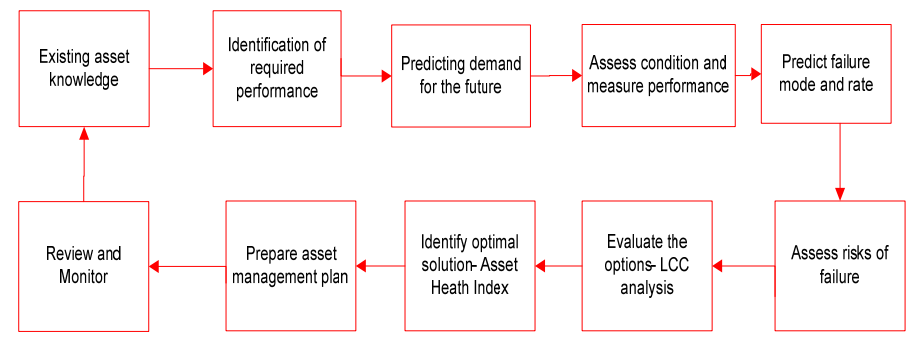

Figure 3: Systematic steps for asset management

\section{CONCLUSION}

Asset Management is extremely important for any asset intensive organization. It has a big influence asset life and fulfilling business objectives.

Power transmission networks have been facing tighter conditions similar to many other industries. There is a need for structured and robust model to make correct decisions. It is vital to clearly understand what the business drivers are and what those business drivers do 
mean to lower levels within the business and what is the best way to implement them for the excellence of asset life delivering expected business outcomes.

This paper touched on some of the important challenges power transmission companies have been facing in Australia. General view of asset management within power transmission industry has been outlined. Managing existing assets plays very important role when balancing the business strategies and implementing customer requirements. Proposed model consists of four levels for implementing strategies. However, each organization needs to have its own asset management approach based on the business environment and regulatory conditions they are in. The most important challenge is to be able to convert business objectives to asset management targets and its successful implementation.

\section{REFERENCES}

[1] British Standards Institution, Asset management part 1: specification for the optimized management of physical infrastructure assets, (PAS 55-1) (UK) 2004.

[2] British Standards Institution, Asset management part 1: specification for the optimized management of physical infrastructure assets, (PAS 55-2) (UK) 2004.

[3] John Woodhouse , "Asset Management DecisionMaking", Plant Maintenance Magazine Article, June 2001.

[4] R.E Brown, B.G Humphrey., "Asset Management for Transmission and Distribution", IEEE Power \& Energy Magazine, May/June 2005.

[5] Powerlink Asset Management Strategy, Queensland, 2006.

[6] K Morton., "Asset Management in the electricity supply industry", Power Engineering Journal, October 1999

[7] www.cigre.org, accessed on the $15^{\text {th }}$ of January 2008

[8] www.epri.com accessed on the 23rd of October 2007

[9] O'Connor P.D.T., Practical Reliability Engineering, Forth Edition, John Wiley \& Sons Ltd, ISBN 10: 0470-84462-0 (UK) 2002.

[10] www.aer.com accessed on the $2^{\text {nd }}$ of January 2008

[11] Dr. M Schwan, Siemens G, PTD SE PTI, Power Transmission and Distribution, Issue 6, 2007.

[12] S.K Mohapatra., S Mukhopadhyay., "Risk and Asset Management of Transmission system in a reformed power sector", IEEE, 2006.

[13] MJ Schwan, K Shilling, U Zickler, A Schneeler., "Component Reliability Prognosis in Asset Management Methods", IEEE, (2006)

[14] Hoskins R.P, Brint A.T, Strbac G, "A structured approach to asset management within the electricity industry", Pergamon, Utilities Policy, 1999.

[15] Western Power, Asset Management Report, 2006. 